\title{
ISOLATION OF EpH4 MAMMARY EPITHELIAL CELL SUBPOPULATIONS WHICH DIFFER IN THEIR MORPHOGENETIC PROPERTIES
}

\author{
R. MONTESANO, ${ }^{1}$ J. V. SORIANO, I. FIALKA, AND L. ORCI \\ Department of Morphology, University of Geneva Medical Center, Geneva, Switzerland (R. M., J. V. S., L. O.); and Research Institute of \\ Molecular Pathology, Vienna, Austria (I. F.)
}

(Received 30 June 1997; accepted 2 October 1997)

SUMMARY

EpH4 is a nontumorigenic cell line derived from spontaneously immortalized mouse mammary gland epithelial cells (Fialka et al., 1996). When grown in collagen gels, EpH4 cells give rise to different types of structures, e.g., solid cords or branching tubes. By removing and subsequently dissociating single three-dimensional colonies of defined morphology, we have isolated six clonal subpopulations of $\mathrm{EpH} 4$ cells which display distinct morphogenetic properties in collagen gel cultures. Thus, cells from the $\mathrm{H}_{1} B$ clone form branching cords devoid of a central lumen, $\mathrm{K}_{3} \mathrm{~A}_{3}$ cells form cords enclosing small multifocal lumina, and $\mathrm{J}_{3} \mathrm{~B}_{1}$ cells form large cavitary structures containing a wide lumen. $\mathrm{I}_{3} \mathrm{G}_{2}$ cells form either cords or tubes, depending on the type of serum added to the culture medium. Finally, when grown in serum-free medium, Bela cells form spherical cysts, whereas Be4a cells form long, extensively branched tubes. In additional assays of morphogenesis, i.e., cell sandwiching between two collagen gels or culture on a thick layer of Matrigel (a laminin-rich extracellular matrix), all clones form epithelial-cell-lined cavitary structures, except $\mathrm{H}_{1} \mathrm{~B}$ cells which are unable to generate lumina under these conditions. The EpH4 sublines we have isolated provide an in vitro system for studying the mechanisms responsible for lumen formation and branching morphogenesis, as well as for identifying the factors which subvert these developmental processes during mammary carcinogenesis.

Key words: cell cloning; extracellular matrix; collagen gel; Matrigel.

\section{INTRODUCTION}

The postnatal development of the mammary gland involves a tightly scheduled sequence of morphogenetic processes, which include the elongation and branching of lactiferous ducts and the subsequent budding of alveoli from the growing ducts (reviewed by Daniel and Silberstein, 1987). These events can be recapitulated in vitro by growing mammary epithelial cells (either in primary culture or as established cell lines) within reconstituted three-dimensional matrices (see for example Yang et al., 1980; Barcellos-Hoff et al., 1989; Darcy et al., 1991; Kanazawa and Hosik, 1992; Petersen et al., 1993; Soriano et al., 1995). Thus, when embedded in collagen gels, a number of immortalized mammary epithelial cell lines have been reported to form histotypic structures resembling branching ducts or alveoli (Ormerod and Rudland, 1982; Danielson et al., 1984; Reichmann et al., 1989; Soule et al., 1990; Berdichevsky et al., 1994; Keely et al., 1995; Soriano et al., 1995).

Because the orderly architecture of mammary gland tissue is disrupted during the development of breast cancer, it is important to develop experimental models in which to study the mechanisms that subvert the normal morphogenetic program of mammary epithelial cells. The nontumorigenic Epl (Reichmann et al., 1992) and EpH4 (Fialka et al., 1996; Oft et al., 1996) cell lines, derived from spon-

${ }^{1}$ To whom correspondence should be addressed at Département de Morphologie, Centre Médical Universitaire, I, rue Michel-Servet, 1211 GENEVE 4 , SUISSE. taneously immortalized mouse mammary cells (Reichmann et al., 1989), provide a powerful tool for the identification of factors that modulate epithelial architecture. Epl and EpH4 cells exhibit a fully polarized epithelial phenotype (as revealed by their high transepithelial electrical resistance and appropriate localization of apical and basolateral marker proteins), and form branching tubular structures when grown in collagen gels. These differentiated properties are however lost following the experimental induction of activated protooncoproteins. Thus, in epithelial tubes formed by $\mathrm{EpH} 4$ cells in collagen gels, activation of $c$-Jun protein results in redistribution of polarity markers, disappearance of the central lumen, and formation of solid cord-like structures (Fialka et al., 1996). Activation of c-Fos oncoprotein induces more pronounced changes, including the acquisition of invasive properties and conversion to a fibroblastoid phenotype (Reichmann et al., 1992). Similar alterations are observed upon incubation of nontransformed $\mathrm{EpH} 4$ cells with thyroid hormone (Lopez-Barahona et al., 1995), or upon incubation of Ha-Ras-EpH4 cells with transforming growth factor beta-1 (Oft et al., 1996).

A complementary approach for identifying molecular determinants of normal and aberrant morphogenesis could involve a comparative analysis of subpopulations derived from the same mammary epithelial cell line, yet differing in their organizational behavior in threedimensional substrata. As an initial step towards this goal, we have isolated six subclones of EpH4 cells which exhibit distinct morphogenetic properties. Here we describe the characterization of these clones with respect to their ability to form lumina and to undergo branching morphogenesis in reconstituted extracellular matrices. 


\section{Materials and Methods}

Culture of EpH4 cells. Parental EpH4 cells (Fialka et al., 1996) were grown in tissue culture flasks (Falcon, Becton-Dickinson, San José, CA) in Dulbecco's modified Eagle's medium (DMEM, GIBCO, Basel, Switzerland) supplemented with $10 \%$ fetal calf serum (FCS, GIBCO) and $2 \mathrm{~m} M$ L-glutamine (this medium will heretofore be referred to as complete medium). For collagen gel cultures, EpH4 cells were harvested with trypsin-EDTA, centrifuged, and suspended in three-dimensional collagen gels as described (Montesano et al., 1983; Montesano et al., 1991). In brief, 8 volumes of rat tail tendon collagen solution (approximately $1.5 \mathrm{mg} / \mathrm{ml}$ ) were mixed with 1 volume of $10 \times$ concentrated minimal essential medium (GIBCO) and 1 volume of sodium bicarbonate $(11.76 \mathrm{mg} / \mathrm{ml})$ in a sterile flask kept on ice to prevent premature collagen gelation. Cells were resuspended in the cold mixture, and either 0.4 $\mathrm{ml}$ or $2 \mathrm{ml}$ aliquots of cell suspension were dispensed into $16-\mathrm{mm}$ wells (Nunc, Kamstrup, Roskilde, Denmark) or 35-mm dishes (Nunc), respectively. After 10 min incubation at $37^{\circ} \mathrm{C}$ to allow collagen gelation, complete medium was added and changed every 2-3 d.

Establishment of EpH4 subclones. Subclones of parental $\mathrm{EpH} 4$ cells were obtained, as described below, by a two-step procedure involving: a) removal of an epithelial colony of defined morphology from a collagen gel culture, followed by its enzymatic dissociation into single cells, and b) cloning of the resulting cell population by limiting dilution.

To facilitate the removal of individual colonies from collagen gel cultures, parental EpH4 cells were suspended at very low density $(100-200 \mathrm{cells} / \mathrm{ml})$ in a collagen solution cast into $35-\mathrm{mm}$ dishes, and subsequently incubated in complete medium for 10-14 d. Colonies of different morphology (e.g., solid branching cords, cords containing small multifocal lumina, or tubulocystic structures with widely patent lumina) were identified by phase-contrast optics with a Nikon Diaphot TMD inverted photomicroscope and delimited by a eircle drawn on the underside of the dish. Collagen gel fragments containing a single colony were manually removed under sterile conditions with the aid of fine forceps and subsequently digested by a $10-\mathrm{min}$ incubation with $4 \mathrm{mg}$ Clostridium histolyticum collagenase per ml (Worthington Biochemical Corporation, Freehold, NJ) as previously described (Soriano et al., 1995). The released epithelial colonies were dissociated into single cells with trypsinEDTA, and the resulting cell suspension was plated into $16-\mathrm{mm}$ wells in complete medium. At confluence, the cells were trypsinized, expanded successively in tissue culture dishes and flasks, and frozen. In some cases, cells obtained by this procedure were suspended once again in collagen gels and subjected to a second cycle of colony isolation and dissociation.

In additional experiments, colonies were isolated from collagen gel cultures performed under serum-free conditions, as follows: EpH4 cells were suspended in collagen gels at $300-500$ cells $/ \mathrm{ml}$ and incubated with a serumfree medium composed of mammary epithelial cell basal medium (MEBM, Clonetics Corporation, San Diego, CA), 0.4\% bovine pituitary extract (Collaborative Biomedical Products, Bedford, MA), $2 \mu \mathrm{g}$ insulin/ml (Sigma Chemical Co., St. Louis, MO), $1 \mu M$ isoproterenol (Sigma), 25 ng hydrocortisone per ml (Sigma) and $2.5 \mathrm{ng}$ transforming growth factor alpha per ml (Bachem, Bubendorf, Switzerland) (Fialka et al., 1996). The colonies developed under serum-free conditions were then isolated and dissociated as described above.

To ensure the monoclonality of cell populations obtained through colony isolation, we devised a novel limiting dilution procedure, which will be referred to as "droplet cloning." Cells were harvested from confluent monolayer cultures with trypsin-EDTA, centrifuged, resuspended in complete medium, and diluted to a density of 50 cells $/ \mathrm{ml}$. A single $20-\mu \mathrm{l}$ droplet of cell suspension (theoretically containing one cell) was placed in the center of each of several 35-mm dishes, within a 5-mm circle drawn on the dish underside. Following a 20 -min incubation at $37^{\circ} \mathrm{C}$ to allow cell attachment, the droplets were carefully inspected by phase-contrast microscopy, and dishes with a droplet containing either no cells or more than one cell were discarded. The remaining dishes, which contained a single cell, were incubated at $37^{\circ} \mathrm{C}$ for a further 90-120 min to allow cell spreading, at which time $2 \mathrm{ml}$ complete medium was added. The circular area in which the droplet was initially deposited was reexamined to confirm the presence of one cell, and the dishes were incubated at $37^{\circ} \mathrm{C}$ for $1-2$ wk to allow formation of colonies approximately $1 \mathrm{~mm}$ in diameter. These were subsequently trypsinized within glass rings and the resulting clonal populations expanded and frozen.

Morphogenetic assays. To assess the morphogenetic properties of EpH4 subpopulations, cells from each clone were suspended in three-dimensional collagen gels at a concentration of $5 \times 10^{3}$ to $2 \times 10^{4}$ cells $/ \mathrm{ml}$ and grown for 1 to $3 \mathrm{wk}$. The morphology of the resulting colonies was monitored by phase contrast opties and further evaluated by light and electron microscopy after fixation and embedding (see below).

The potential ability of the various clones to form lumina was more specifically assessed by "sandwiching" the cells between two collagen layers. Cells were seeded at $1-2 \times 10^{5}$ cells per $35-\mathrm{mm}$ dish onto the surface of a collagen gel $(1 \mathrm{ml})$ and grown to near confluence $(2-3 \mathrm{~d})$. The monolayer was subsequently overlaid with a second $1 \mathrm{ml}$ collagen gel as described by Montesano et al. (1983) and incubated at $37^{\circ} \mathrm{C}$ for a further $6-7 \mathrm{~d}$.

An additional assay of morphogenetic behavior consisted in seeding the cells onto a thick layer of Matrigel, a laminin-rich matrix derived from the Engelbreth-Holm-Swarm (EHS) tumor (Kleinman et al., 1986). First, 150- $\mu \mathrm{l}$ aliquots of Matrigel (Collaborative Biomedical Products) were dispensed onto a preformed $250-\mu \mathrm{l}$ collagen gel (base layer) and allowed to gel at $37^{\circ} \mathrm{C}$ for $30 \mathrm{~min}$. Cells from the various clones were then plated onto the Matrigel surface at concentrations ranging from $2 \times 10^{4}$ to $1 \times 10^{5}$ cells/well. Alternatively, the cells were seeded onto a 125- $\mu$ l layer of Matrigel, allowed to attach for $30 \mathrm{~min}$, and subsequently covered with a second layer of Matrigel $(150 \mu \mathrm{l})$. Complete medium was then added on top of the gelified Matrigel.

Processing for light and electron microscopy. Collagen or Matrigel cultures were fixed in situ overnight with $2.5 \%$ glutaraldehyde in $0.1 \mathrm{M}$ sodium cacadylate buffer ( $\mathrm{pH} 7.4$ ). After extensive rinsing in the same buffer, the gels were gently removed from the dishes or wells and cut into $3-\times 3-\mathrm{mm}$ fragments. These were postfixed in $1 \%$ osmium tetroxide in Veronal acetate buffer for 45 min, stained en bloc with $2.5 \%$ uranyl acetate in $50 \%$ ethanol, dehydrated in graded ethanols, and embedded in Epon 812 as described (Montesano et al., 1991). Semithin (1- $\mu$ m-thick) sections were cut with an LKB Ultramicrotome, stained with $1 \%$ methylene blue, and photographed under transmitted light with a Zeiss photomicroscope. Thin sections were stained with uranyl acetate and lead citrate and examined with a Philips CM 10 electron microscope.

\section{RESULTS}

This study was prompted by the finding that EpH4 mammary epithelial cells (Fialka et al, 1996) form different types of three-dimensional structures when grown in collagen gels in serum-supplemented medium (Fig. 1). In cultures examined by phase-contrast microscopy, the majority of the epithelial colonies consisted of solid cords apparently devoid of lumen (Fig. 1 a). A number of colonies, however, contained either multifocal lumen-like spaces (Fig. $1 b$ ) or widely patent cylindrical lumina virtually occupying the entire cord width (Fig. $1 \mathrm{c}$ ). Conceivably, these morphologically different structures could develop from a homogeneous cell population, either because of local variations in culture microenvironment or as sequential phases in colony evolution. Alternatively, they could result from the clonal growth of phenotypically distinet cells.

To discriminate between these two possibilities, we set out to assess the morphogenetic properties of clonal cell populations derived from individual colonies. Single three-dimensional structures exhibiting a well-defined morphotype (e.g., solid cords, cords with multifocal lumina, and tubes with a wide lumen; see Fig. 1) were removed from low density collagen gel cultures (see Materials and Methods) and enzymatically dissociated. The resulting cell populations were then expanded and assayed for their organizational behavior in collagen gels. The finding that each cell subpopulation formed threedimensional structures similar to the colony from which it was initially isolated supported the view that the $\mathrm{EpH} 4$ cell line is composed of phenotypically distinct epithelial cells. However, because the populations obtained by colony isolation were not demonstrated to have a monoclonal origin, they were recloned with an improved limiting dilution procedure ("droplet cloning"; see Materials and Methods). Four clones (designated $\mathrm{H}_{1} \mathrm{~B}, \mathrm{I}_{3} \mathrm{G}_{2}, \mathrm{~J}_{3} \mathrm{~B}_{1}$ and $\mathrm{K}_{3} \mathrm{~A}_{3}$ ), each of which gave rise to a different type of colony in collagen gels (see below), were selected for further characterization. In light of our previous funding that epithelial cells suspended in collagen gels can form col- 

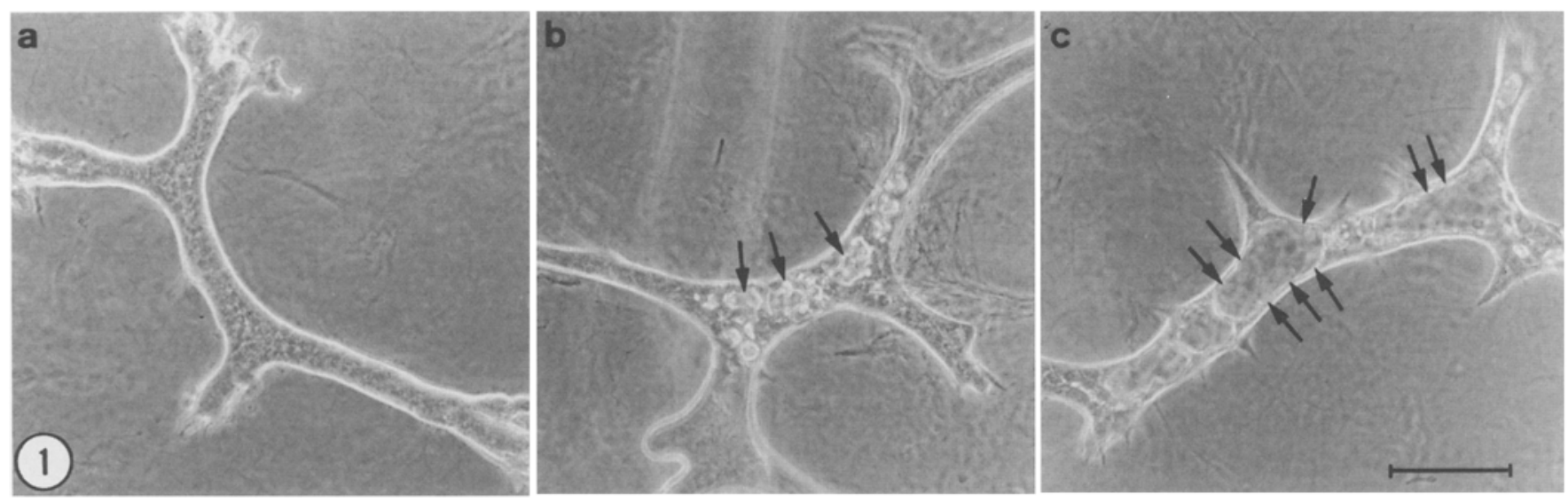

FIG. 1. Parental EpH4 cells form different types of three-dimensional structures in collagen gels. EpH4 cells were suspended in a collagen gel at a concentration of $5 \times 10^{3} \mathrm{cells} / \mathrm{ml}$ and incubated in FCS-supplemented DMEM for $7 \mathrm{~d}$, at which time colonies of different morphology were photographed with an inverted phase-contrast microscope. (a) Predominant type of colony consisting of smooth-surfaced branching cords devoid of a visible lumen; (b) flattened cords containing multiple small lumina (arrows); (c) thin-walled tube-like structure containing a wide lumen (arrows), $B a r=100 \mu \mathrm{m}$.

onies of different morphology depending on whether they are grown in the presence of fetal calf serum (FCS) or donor calf serum (DCS) (unpublished observations), the behavior of EpH4 clones was assessed in both culture conditions.

Cell suspension in three-dimensional collagen gels. When embedded in collagen gels, $\mathrm{H}_{1} \mathrm{~B}$ cells gave rise to long branching cords devoid of central lumen, irrespective of whether the culture medium (DMEM) was supplemented with FCS or DCS (Fig. $2 a-c$ ). In contrast, the behavior of clone $\mathrm{I}_{3} \mathrm{G}_{2}$ was highly dependent on the type of serum added to the cultures: in the presence of FCS, $\mathrm{I}_{3} \mathrm{G}_{2}$ cells formed solid, flattened cords which occasionally contained tiny lumen-like spaces (Fig. $2 d$ ), whereas in the presence of DCS, they formed branching tubes containing a wide lumen (Fig. 2 eff). $\mathrm{J}_{3} \mathrm{~B}_{1}$ cells formed cavitary structures, whose morphology ranged from short ectatic tubes (in FCS; not shown) to irregularly-shaped cysts (in DCS; Fig. $2 g, h)$. Finally, $K_{3} A_{3}$ cells gave rise to branching cords containing numerous heterogeneously-sized multifocal lumina, which were usually larger in DCS than in FCS (Fig. $2 i-k$ ). Thus, suspension in collagen gels in serum-supplemented medium demonstrated first that the four $\mathrm{EpH} 4$ clones described above differ in their morphogenetic properties, and second that DCS is superior to FCS in promoting lumen formation (except for $\mathrm{H}_{1} \mathrm{~B}$ cells, which are apparently incapable of forming lumina in collagen gels).

Because parental EpH4 cells have been reported to form branching tubes when grown in collagen gels in serum-free medium (Fialka et al., 1996; Oft et al., 1996), we also assessed the behavior of EpH4 clones in serum-free culture. Surprisingly, all four clones examined proliferated slowly under these conditions, and in no instances were tubular structures formed (results not shown). This finding led us to hypothesize that the procedure of isolating colonies formed in serumcontaining cultures had selected for $\mathrm{EpH} 4$ subpopulations other than those which have the ability to generate branching tubes in serumfree medium. To explore this possibility, parental $\mathrm{EpH} 4$ cells were allowed to form three-dimensional structures in serum-free collagen gel cultures, at which time individual colonies were removed and enzymatically dissociated. The cell populations thus obtained were subsequently cloned by the "droplet" method, and the resulting clones were assayed for their morphogenetic properties in collagen gels. Two clones capable of forming cavitary structures (clones Bela and Beta) were further characterized. When grown in collagen gels in serum-free medium, Bela cells gave rise to spherical cysts (Fig. $3 a, c)$, whereas Be4a cells formed extensively branched cords containing multifocal or continuous lumina (Fig. 3 b,d). Bela and Be4a cells also exhibited a different organizational behavior in serumsupplemented cultures. Thus, in the presence of DCS, Bela cells formed slowly growing cystic structures, whereas Be4a cells formed branching tubes (not shown).

In summary, the four clones $\left(\mathrm{H}_{1} \mathrm{~B}, \mathrm{I}_{3} \mathrm{G}_{2}, \mathrm{~J}_{3} \mathrm{~B}_{1}\right.$, and $\left.\mathrm{K}_{3} \mathrm{~A}_{3}\right)$ established from $\mathrm{EpH} 4$ colonies formed in serum-supplemented cultures, as well as the two clones (Bela and Be4a) established from $\mathrm{EpH} 4$ colonies formed under serum-free conditions, were found to differ considerably in their ability to undergo branching morphogenesis and to form lumina when suspended in three-dimensional collagen gels (Table 1).

Response to collagen gel overlay. Because the clones described above differed markedly in their capacity to form lumina when suspended in collagen gels, we investigated this property in more detail using the collagen sandwich technique. When polarized epithelial cells are grown on a collagen gel and subsequently overlaid with a second layer of collagen, the initial monolayer undergoes a profound reorganization which culminates in the creation of newly formed lumina (Chambard et al., 1981; Hall et al., 1982; Schwimmer and Ojakian, 1995; Zuk and Matlin, 1996). To study the response of $\mathrm{EpH} 4$ clones to collagen overlay, cells were seeded onto the surface of a collagen gel and grown to near confluence, at which time the monolayer was covered with an additional collagen gel. Irrespective of whether the culture medium (DMEM) was supplemented with FCS or with DCS, collagen overlay induced lumen formation by all clones except $\mathrm{H}_{\mathrm{t}} \mathrm{B}$ cells (Fig. 4, Table $\mathbf{1}$ ). Lumen formation was first detectable approximately $2 \mathrm{~d}$ following collagen overlay as small refractile spaces between adjacent cells (not shown). Over the next few days of culture, these spaces increased in number, enlarged, and coalesced to form wider cavities (shown for $\mathbf{J}_{3} \mathrm{~B}_{1}$ cells in Fig. $4 \mathrm{a}$ ). Sections perpendicular to the culture plane showed that the cavities 


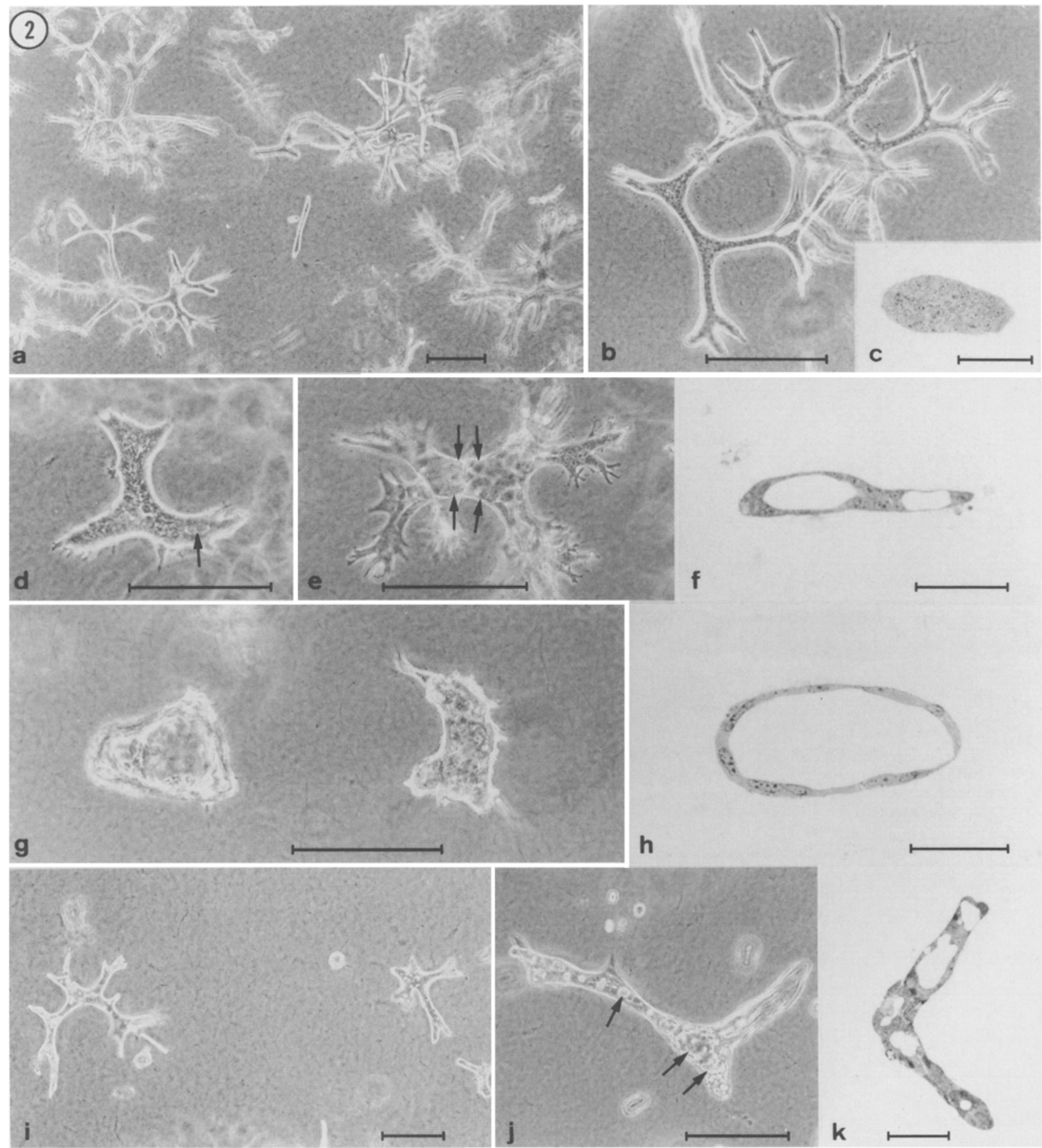

FIG. 2. Clones established from different types of $\mathrm{E}_{\mathrm{pH}} 4$ colonies exhibit distinct morphogenetic properties. Four clones isolated from EpH4 colonies formed in FCS-supplemented DMEM were suspended in collagen gels and grown either in DMEM + FCS or in DMEM + DCS. (a) Cells from the $\mathrm{H}_{1} \mathrm{~B}$ clone grown in the presence of DCS form solid branching cords; $(b)$ higher magnification of a colony of $\mathrm{H}_{1} \mathrm{~B}$ cells; $(c)$ semithin section of a cord of $\mathrm{H}_{1} \mathrm{~B}$ cells showing the lack of a central lumen. $(d) \mathrm{I}_{3} \mathrm{G}_{2}$ cells grown in FCS-supplemented medium form flattened solid cords which occasionally contain small lumen-like translucent spaces (arrow); $(e) I_{3} G_{2}$ cells grown in DCSsupplemented medium form branched structures containing a widely patent lumen; $(f)$ semithin section of the culture shown in $(e)$ confirming the tubular nature of $\mathrm{I}_{3} \mathrm{G}_{2}$ colonies. $(g, h)$ large cyst-like structures formed by $\mathrm{J}_{3} \mathrm{~B}_{1}$ cells grown in the presence of DCS. $\mathrm{K}_{3} \mathrm{~A}_{3}$ cells grown in the presence of FCS $(i, j)$ or DCS $(k)$ form branching cords containing multifocal lumina of various sizes. Bars correspond to $200 \mu \mathrm{m}$ for phase-contrast micrographs $(a, b, d, e, g, i$, and $j)$ and to $50 \mu \mathrm{m}$ for semithin sections $(c, f, h$, and $k)$. 

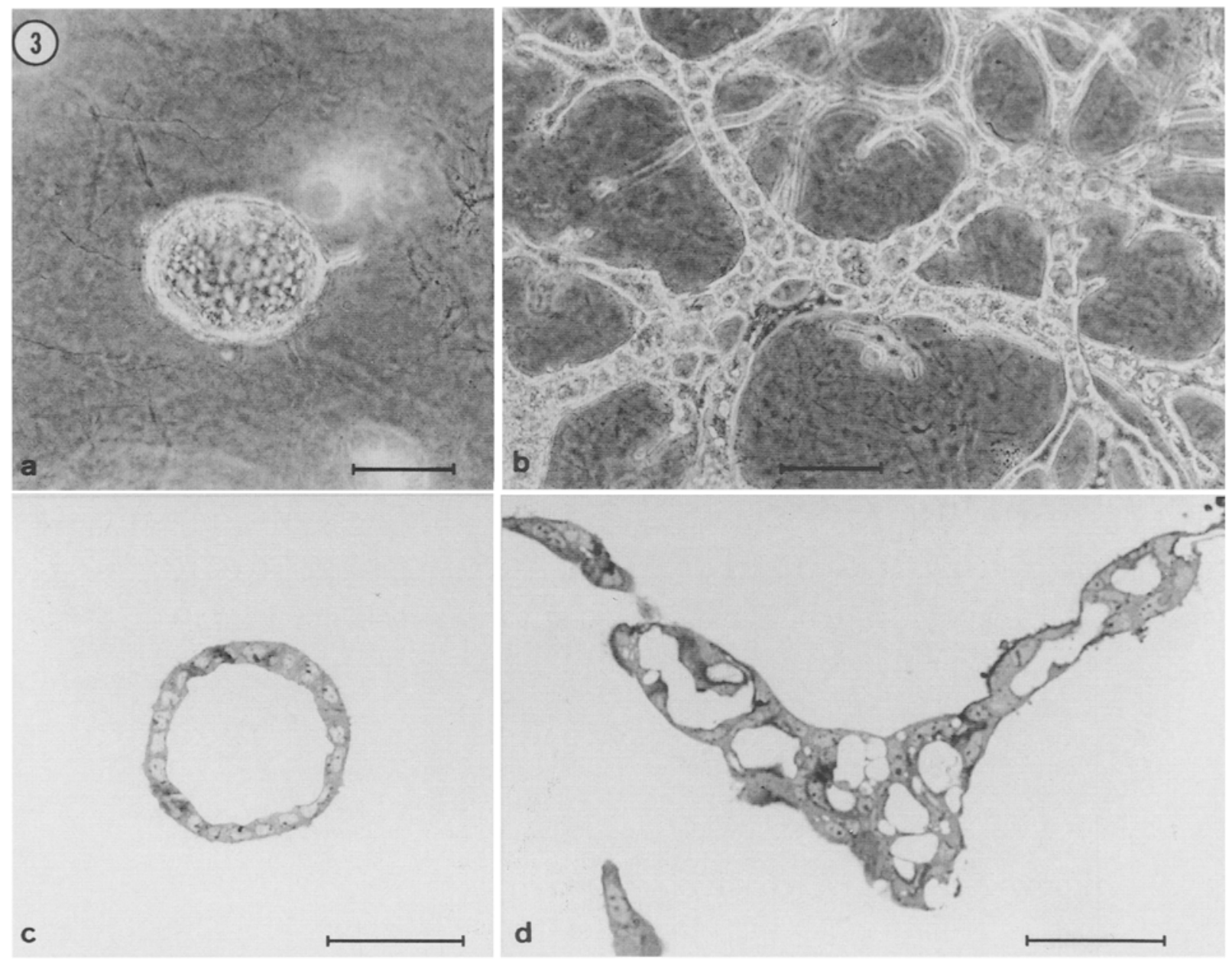

FIG. 3. Morphogenetic properties of clones Bela and Be4a. Unlike the four clones illustrated in Figure 2, clones Bela and Be4a were established from colonies of EpH4 cells formed under serum-free culture conditions (see Materials and Methods). (a.c) When suspended in collagen gels in senum-free medium. Bela cells form spherical cysts; $(b, d)$ Under the same experimental conditions, Be4a cells form long branching cords containing clearly defined lumina. $(a, b)$ Bars $=100 \mu \mathrm{m} ;(c, d)$ Bars $=50 \mu \mathrm{m}$.

TABLE 1

SYNOPTIC VIEW OF THE MORPHOGENETIC PROPERTIES OF EPH4 CLONES

\begin{tabular}{|c|c|c|c|c|}
\hline Clones & $\begin{array}{c}\text { Behavior } \\
\text { in collagen gels }\end{array}$ & $\begin{array}{l}\text { Lumen } \\
\text { formation } \\
\text { in collagen } \\
\text { sandwich }\end{array}$ & $\begin{array}{c}\text { Dome } \\
\text { formation } \\
\text { on plastic }\end{array}$ & $\begin{array}{l}\text { Lumen } \\
\text { formation } \\
\text { in Matrigel }\end{array}$ \\
\hline $\mathrm{H}_{1} \mathrm{~B}$ & Solid branching cords & 一 & + & - \\
\hline $\mathrm{I}_{3} \mathrm{G}_{2}$ & $\begin{array}{l}\text { In FCS: cords with rare small } \\
\text { lumina. In DCS: tubes }\end{array}$ & + & - & + \\
\hline $\mathrm{J}_{3} \mathbf{B}_{1}$ & Tubulocystic structures ${ }^{b}$ & + & - & + \\
\hline $\mathrm{K}_{3} \mathrm{~A}_{3}$ & Cords with multifocal lumina & + & + & + \\
\hline Bela & Spheroidal cysts (in SFM ${ }^{c}$ ) & + & + & + \\
\hline Be4a & $\begin{array}{l}\text { Long, highly branched tubes } \\
\quad\left(\text { in } \mathrm{SFM}^{c}\right)\end{array}$ & + & $+d$ & + \\
\hline
\end{tabular}

${ }^{a}$ For simplicity, only the most salient properties of each clone are indicated. In DCS, lumina are larger than in FCS.

eSFM = serum-free medium.

dDomes are more flattened than in the other clones. seen by phase-contrast microscopy were, in fact, lumina enclosed by two epithelial monolayers, one attached to the upper gel and another to the lower (Fig. $4 c$ ). Ultrastructural analysis revealed that the epithelial cells lining the lumen were correctly polarized and provided with apical microvilli (not shown). In sharp contrast, collagen overlay did not elicit lumen formation by $\mathrm{H}_{1} \mathrm{~B}$ cells (Fig. $4 b, d$ ). Instead, cells migrated from the sandwiched monolayer into the upper collagen gel (Fig. 4 b). The inability of $\mathrm{H}_{1} B$ cells to form lumina in response to collagen overlay therefore correlates with the finding that these cells form solid cords when suspended in collagen gels (Fig. $2 a-c$ ).

Dome formation in conventional monolayer culture. Like other polarized epithelial cell lines (see, for example, Wohlwend et al., 1986), parental $\mathrm{EpH} 4$ cells generate fluid-filled blisters, or domes, when grown on an impermeable substratum. We wished to determine whether the differential ability of $\mathrm{EpH} 4$ clones to form lumina in collagen gels would correlate with the ability to form domes on tissue culture plastic. In postconfluent cultures, $\mathrm{H}_{1} \mathrm{~B}, \mathrm{~K}_{3} \mathrm{~A}_{3}$, Bela, and Be $4 \mathrm{a}$ cells formed numerous domes (shown in Fig. 5 a for Bela cells). In contrast, domes were not observed in monolayers of either $I_{3} G_{2}$ (not 


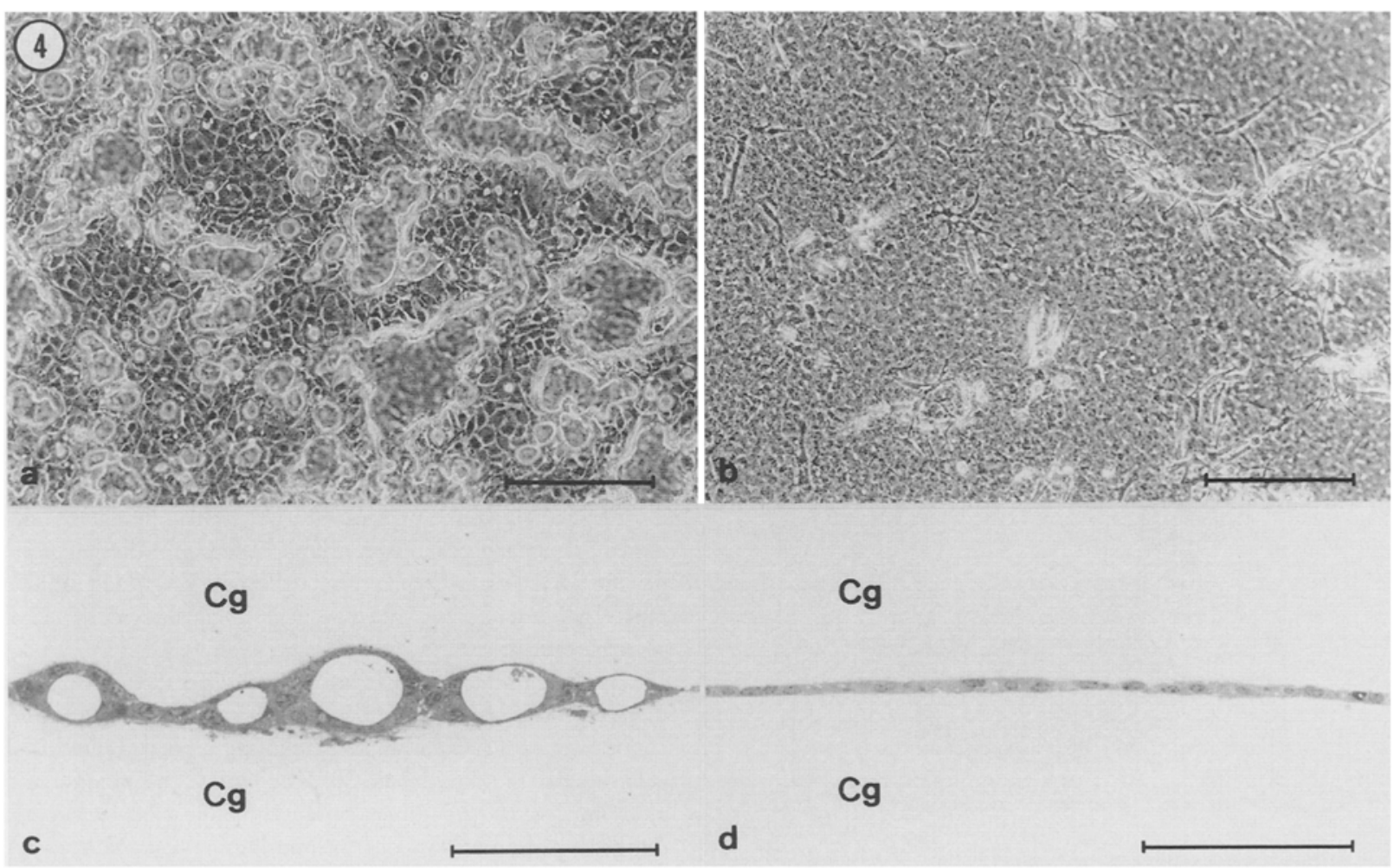

FIG. 4. Differential response of EpH4 subclones to collagen overlay. Cells were grown on a collagen gel until a nearly confluent monolayer was obtained, and were subsequently covered with a second collagen gel, as described in Materials and Methods. $(a)$ Four days following collagen overlay, $\mathrm{J}_{3} \mathbf{B}_{1}$ cells have formed numerous irregularly-shaped cavities delimited by refringent borders; $(b)$ six days following collagen overlay, $\mathrm{H}_{1} \mathrm{~B}$ cells have not formed cavities (notice that a number of elongated cells have migrated from the sandwiched monolayer into the upper collagen gels); (c) cross-section of a culture similar to that shown in $(a)$ demonstrating that $\mathrm{J}_{3} B_{1}$ cells have reorganized between the two collagen layers to form multiple lumina; $(d)$ cross-section of the culture in $(b)$ demonstrating the lack of lumen formation by $\mathrm{H}_{1} \mathrm{~B}$ cells. $(a, b):$ Bars $=200 \mu \mathrm{m} ;(c, d):$ Bars $=100 \mu \mathrm{m}$.

shown) or $\mathrm{J}_{3} \mathrm{~B}_{1}$ cells (Fig. $5 \mathrm{~b}$ ), even when the cultures were maintained for as long as $3 \mathrm{wk}$ after confluence. These findings indicate that lumen formation in collagen gels and dome formation in conventional monolayer culture are unrelated phenomena.

Behavior of $E_{p} H 4$ clones on Matrigel. Culture of mammary epithelial cells on Matrigel, a reconstituted laminin-rich matrix extracted from the EHS tumor (Kleinman et al., 1986), has been shown to result in the formation of well organized, alveolar-like "mammospheres" (Barcellos-Hoff et al., 1989; Petersen et al., 1993; Hurley et al., 1994). To establish whether EpH4 subpopulations would differ in their ability to form three-dimensional structures on this substrate, cells from each clone were seeded onto a thick layer of Matrigel and incubated for 10-15 $\mathrm{d}$ in complete medium. Cells from all clones attached rapidly to the gel and initially had a homogeneous distribution on the substrate. During the next few hours of incubation, however, the cells progressively associated with each other, so that by $24 \mathrm{~h}$ they had clustered into compact multicellular aggregates. The nature of the structures formed on Matrigel was dependent on plating density. When seeded onto the gel at a concentration of $1 \times$ $10^{5}$ cells per $16-\mathrm{mm}$ well, the cells organized into a network of anastomosing cords (not shown). In contrast, at plating densities of $2 \times$ $10^{4}$ cells/well, cells from all clones clustered into discrete cell aggregates (Fig. 6 a). Similar density-dependent differences in associative behavior have previously been reported for other mammary epithelial cells grown on Matrigel (Stahl et al., 1997). Although the network of cords formed in high density cultures showed little modification following extended incubation, the structures formed after low-density seeding underwent clearly identifiable changes. Cell aggregates induced a rearrangement of the surrounding matrix, which was recognizable as a dense array of radially disposed striations (Fig. 6 a) surrounding each aggregate. Matrigel remodeling has been shown in other systems to result from a process of cell traction on the substrate (Vernon et al., 1992). Daily examination of the cultures after seeding showed that the aggregates gradually sank into the malleable matrix and became ensheathed by a thick layer of reorganized Matrigel. Concomitantly with the invasion of the underlying substrate, the aggregates underwent a process of cavitation which within $1-2$ wk resulted in the formation of cystic structures (Fig. 6 b). The latter were often connected by a stalk to a cluster of cells remaining on the surface of the gel (Fig. $6 d, e$ ). As previously described for primary mammary epithelial cells (Barcellos-Hoff et al., 1989), the lumen of the cysts was delimited by a layer of cubic or columnar epithelial cells (Fig. $6 c-e$ ), which were provided with junctional complexes and numerous apical microvilli (Fig. 7). Cyst formation in Matrigel was observed with all EpH4 clones except $\mathrm{H}_{1} \mathrm{~B}$ cells, which gave rise to solid ball-like structures that only occasionally contained small lumen-like spaces (not shown). Likewise, when 


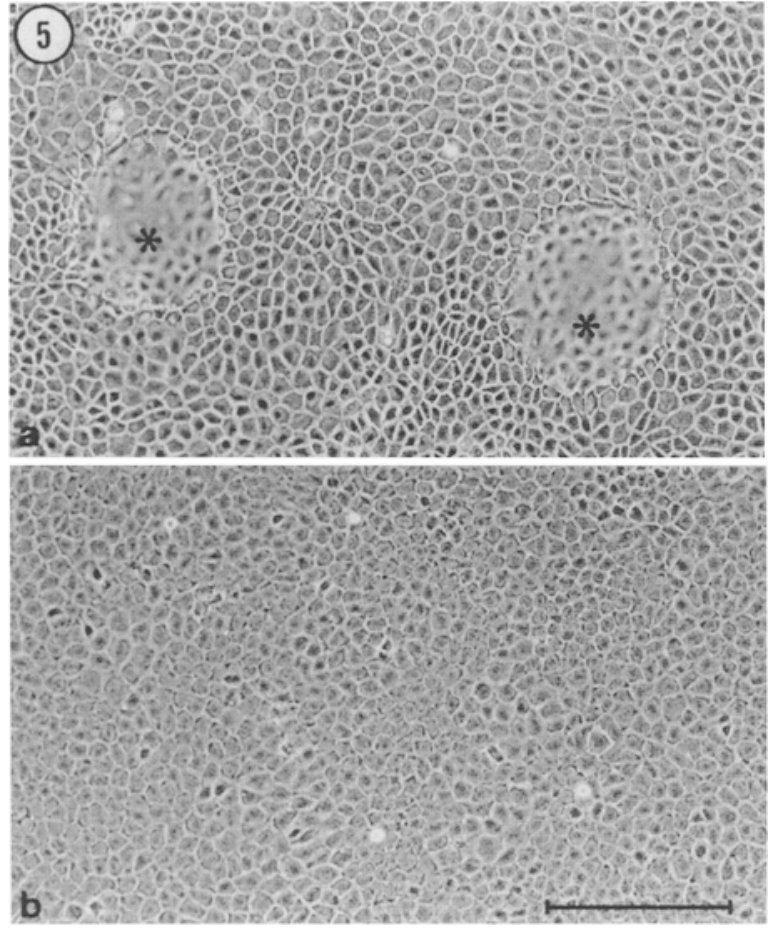

FIG. 5. EpH4 subclones differ in their ability to form domes. Cells were seeded into 35-mm dishes and grown to postconfluence. (a) Bela cells maintained in culture for $11 \mathrm{~d}$ have generated characteristic blisters or domes (asterisks); (b) $\mathrm{J}_{3} \mathrm{~B}_{1}$ cells maintained in culture for $13 \mathrm{~d}$ have not formed domes (the same culture was reexamined $10 \mathrm{~d}$ later and found to be totally devoid of domes). Bar $=200 \mu \mathrm{m}$.

sandwiched between two Matrigel layers, all clones formed spherical cysts (shown in Fig. $6 f$ for $\mathrm{I}_{3} \mathrm{G}_{2}$ cells), except $\mathrm{H}_{1} \mathrm{~B}$ cells, which formed small lumen-less aggregates (Fig. $6 \mathrm{~g}$ ). Similar results were obtained when cells from the various clones were suspended into Matrigel (data not shown).

\section{DisCuSSION}

By cloning the EpH4 mammary epithelial cell line, we have isolated six cell subpopulations which display markedly different morphogenetic properties. The most distinctive features of each subclone are summarized below (see also Table 1).

When suspended in collagen gels, $\mathrm{H}_{1} \mathrm{~B}$ cells form smooth-contoured branched cords which superficially resemble mammary gland ducts. The cords, however, lack a central lumen, and the inability of $\mathrm{H}_{1} \mathrm{~B}$ cells to form cavitary structures was confirmed in both the collagen gel sandwich and the Matrigel assay. Interestingly, $\mathrm{H}_{1} \mathrm{~B}$ cells form domes when grown to postconfluence in tissue culture dishes, which indicates that despite their inability to form lumina in threedimensional cultures, these cells have retained some characteristics of the polarized epithelial phenotype.

Unlike $\mathrm{H}_{1} \mathrm{~B}$ cells, $\mathrm{I}_{3} \mathrm{G}_{2}$ cells form lumen-containing cords in collagen gels. The extent of lumen development, however, is critically dependent on the type of serum added to the culture medium. Whereas in the presence of FCS the cords are mostly solid and only occasionally contain small focal lumina, in the presence of DCS they contain wide lumina and therefore have a tubular structure. These findings indicate that when grown under appropriate conditions, $I_{3} G_{2}$ cells have the capacity to form duct-like structures. The factors in DCS which stimulate lumen formation by $\mathrm{I}_{3} \mathrm{G}_{2}$ cells are not known, but their lack of effect on $\mathrm{H}_{2} \mathrm{~B}$ cells suggests that they can only act on cells which are intrinsically competent to form lumina.

The most characteristic feature of $\mathrm{J}_{3} \mathrm{~B}_{1}$ cells is their ability to form large cavitary structures when suspended in collagen gels. Unlike all other EpH4 clones, $\mathrm{J}_{3} \mathrm{~B}_{1}$ cells form thin-walled branching tubes containing a widely patent continuous lumen when grown in FCS-supplemented medium. Lumen formation is even more prominent in the presence of DCS, under which condition $\mathrm{J}_{3} \mathrm{~B}_{1}$ cells generate large, irregularly-shaped cyst-like structures.

$\mathrm{K}_{3} \mathrm{~A}_{3}$ cells suspended in collagen gels in either FCS or DCS form branching cords containing numerous multifocal spaces, which sometimes coalesce into larger lumina.

Bela cells have the unique ability to form spheroidal cysts when grown in collagen gels in serum-free medium. In sharp contrast, under the same serum-free culture conditions, Be4a cells generate extensively branched duct-like structures enclosing multifocal or continuous lumina.

When the different clones are evaluated for their ability to mimic morphogenetic events occurring during mammary gland development, Be4a cells, which generate highly arborized tubules in collagen gels, appear to more accurately recapitulate the process of ductal morphogenesis. Other clones mimic this process only incompletely, due to their limited capacity to form lumina (e.g., $\mathrm{K}_{3} \mathrm{~A}_{3}$ cells) or to branch (e.g., $I_{3} G_{2}$ and $J_{3} B_{1}$ cells). Finally, a selective deficiency in either lumen formation or branching, which are two essential components of ductal morphogenesis, is observed in clones $H_{1} B$ and Bela, respectively. Thus, while capable of undergoing repetitive branching, $\mathrm{H}_{1} \mathrm{~B}$ cells are unable to form lumina. Conversely, when embedded in collagen gels in serum free-medium, Bela cells form hollow cysts, but lack the ability to branch and generate tube-like structures, in contrast to what is observed with Be4a cells grown under the same conditions.

The spectrum of cell subpopulations present in the parental $\mathrm{EpH}_{\mathrm{p}}$ cell line is unlikely to be restricted to the six phenotypically distinct clones we have isolated. Indeed, besides the prototypic structures illustrated in Figure 1, collagen gel cultures of parental EpH4 cells also contained branching structures consisting of short stubby cords with bulbous extremities, which were reminiscent of mammary gland "end buds." Despite repeated attempts, we have not succeeded in establishing EpH4 subclones capable of forming this type of colony in collagen gels. An additional variety of colony occasionally observed in cultures of parental EpH4 cells consisted of loose associations of spindle-shaped cells. Since these aggregates lacked an epithelial-like organization, we did not attempt to isolate them. Cloning this putative cell subpopulation remains nonetheless an interesting prospect, because spindle-shaped cells may have arisen through a process of epithelial-mesenchymal conversion.

It may be at first glance surprising that as many as six distinct sublines have been isolated from the EpH4 cell line, which was clonally derived (Fialka et al., 1996). It is conceivable, however, that variant subpopulations have arisen during propagation of the original cell line. Notably, in serum-free collagen gel cultures, only Be4a cells exhibit morphogenetic properties similar to those of parental EpH4 cells, which suggests that this clone represents the direct descendants of the originally established EpH4 cells. The other clones we have characterized are instead likely to have been generated by in- 


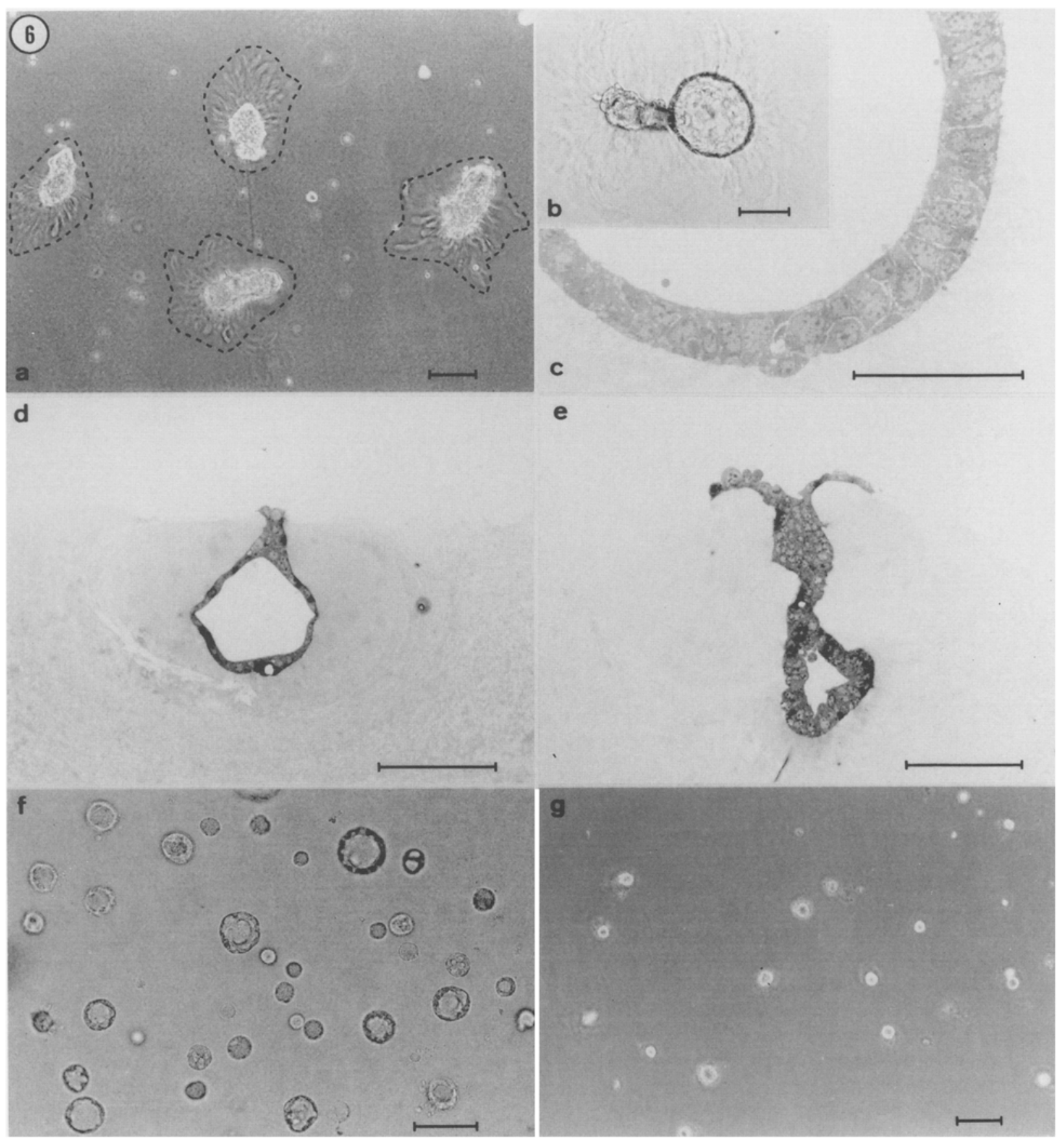

FIG. 6. Morphogenetic behavior of $\mathrm{EpH} 4$ clones grown on Matrigel. (a) Three-dimensional aggregates formed by $\mathrm{J}_{3} \mathrm{~B}_{1}$ cells $48 \mathrm{~h}$ after having been plated on Matrigel at $2 \times 10^{4} \mathrm{cells} / 16-\mathrm{mm}$ well. The hatched lines delimit a zone of substrate remodeling which is recognizable as an array of radially disposed striations surrounding each cell aggregate. (b) Detail of the culture shown in (a) $\mathrm{ll} \mathrm{d}$ after cell seeding. An initially solid cell aggregate has invaded the underlying basement membrane gel and has concomitantly undergone a process of cavitation resulting in the formation of a cystic structure. The aggregate is surrounded by a layer of reorganized Matrigel. (c) Semithin section through a cyst-like structure formed by $J_{3} B_{1}$ cells grown on Matrigel for $10 \mathrm{~d}$. The wall of the cyst is composed by an ordered palisade of cylindrical epithelial cells. $(d, e) \mathrm{I}_{3} \mathrm{G}_{2}$ cells grown for $14 \mathrm{~d}$ on Matrigel have invaded the underlying matrix, into which they have formed cavitary structures. The cystic portion of the colony is connected through a solid stalk to a cluster of cells remaining on the surface of the gel. Notice that the colonies are ensheathed by a thick layer of reorganized Matrigel. $(f) I_{3} G_{2}$ cells were first allowed to attach on Matrigel and subsequently overlaid with a second Matrigel layer. Thirteen d later, the cells have formed numerous cystic structures between the two gel layers. $(g) \mathrm{H}_{1} \mathrm{~B}$ ceils sandwiched between two Matrigel layers as in $(f)$ have formed small aggregates devoid of a central lumen. Bars $=100 \mu \mathrm{m}$, except for (c) where bar $=50 \mu \mathrm{m}$. 


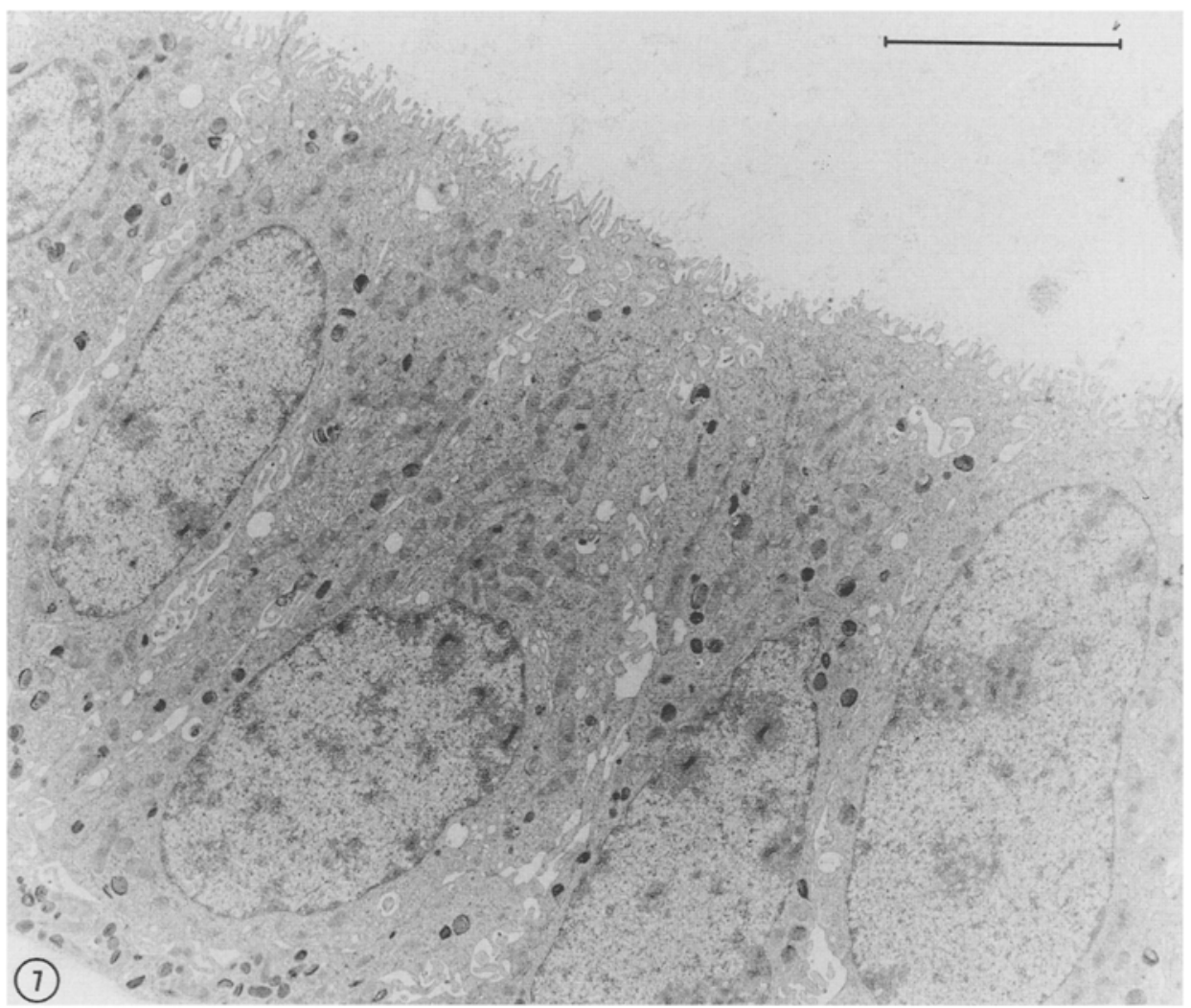

FIG. 7. Thin section across the wall of a cyst formed by $\mathrm{J}_{3} \mathrm{~B}_{1}$ cells grown on Matrigel. The cells have a cylindrical shape and project numerous microvilli towards the lumen of the cyst. Bar $=5 \mu \mathrm{m}$. dependent mutations within an initially homogenous population. It is equally possible that parental $\mathrm{EpH} 4$ cells are not fully differentiated and behave as precursor-like cells (stem cells?) capable of giving rise to phenotypically different subpopulations.

Lumen formation and ductal branching are fundamental events in the morphogenesis of mammary gland and other epithelial tissues (Gumbiner, 1992). However, very little is known about the mechanisms which control these biological processes (Soriano et al., 1995; Yang et al., 1995; Soriano et al., 1996). The EpH4 sublines we have isolated should provide a useful in vitro system for investigating the molecular basis of branching morphogenesis and lumen formation, as well as the factors (e.g., oncoproteins) that disrupt these processes. Thus, a comparative analysis of the expression of potentially relevant proteins (e.g., integrins, extracellular matrix components, proteases/ protease inhibitors) in different $\mathrm{EpH} 4$ subclones may help to elucidate the mechanisms responsible for aberrant morphogenesis, i.e., failure of branching or lack of lumen formation. In addition, the likely common origin of the EpH4 subpopulations described in this study may offer an opportunity for the identification of genes which are differentially expressed by clones endowed with distinct morphogenetic properties.

\section{ACKNOWLEDGMENTS}

We are grateful to J. Rial-Robert for setting up the "droplet cloning" procedure. We also thank M. Eissler for skillful technical assistance, J. P. Gerber for photographic work, F. Hellal for secretarial assistance, and Drs. H. Beug and M. Pepper for their comments on the manuscript. This study was supported by a grant from the Swiss National Science Foundation (number 3143364.95).

\section{REFERENCES}

Barcellos-Hoff, M. H.; Aggeler, J.; Ram, T. G., et al. Functional differentiation and alveolar morphogenesis of primary mammary cultures on reconstituted basement membrane. Development 105:223-235; 1989.

Berdichevsky, F.; Alford, D.; D'Souza, B., et al. Branching morphogenesis of human mammary epithelial cells in collagen gels. J. Cell Sci. 107:3557-3568; 1994.

Chambard, M.; Gabrion, J.; Mauchamp, J. Influence of collagen gel on the orientation of epithelial cell polarity: follicle formation from isolated thyroid cells and from preformed monolayers. J. Cell Biol. 91:157$166 ; 1981$.

Daniel, C. W.; Silberstein, G. B. Postnatal development of the rodent mammary gland. In: Neville, M. C.; Daniel, C. W., ed. The mammary gland. Development, regulation and function. New York: Plenum Press; 1987:3-36.

Danielson, K. G.; Oborn, C. J.; Durban, E. M., et a], Epithelial mouse mammary cell line exhibiting normal morphogenesis in vivo and functional differentiation in vitro. Proc. Natl. Acad. Sci. USA 81:3756-3760; 1984.

Darcy, K. M.; Black, J. D.; Hahm, H. A., et al. Mammary organoids from immature virgin rats undergo ductal and alveolar morphogenesis when grown within a reconstituted basement membrane. Exp. Cell Res. 196:49-65; 1991.

Fialka, I.; Schwartz, H.; Reichmann, E., et al. The estrogen-dependent cJunER protein causes a reversible loss of mammary epithelial cell polarity involving a destabilization of adherens junctions. J. Cell Biol. 132:1115-1132; 1996.

Gumbiner, B. M. Epithelial morphogenesis. Cell 69:385-387; 1992.

Hall, H. G.; Farson, D. A.; Bissell, M. J. Lumen formation by epithelial cell lines in response to collagen overlay: a morphogenetic model in culture. Proc. Natl. Acad. Sci. USA 79:4672-4676; 1982.

Hurley, W. L.; Blatchford, D. R.; Hendry, K. A. K., et al. Extracellular matrix and mouse mammary cell function: comparison of substrata in culture. In Vitro Cell. Dev. Biol. 30A:529-538; 1994. 
Kanazawa, T.; Hosik, H. L. Transformed growth phenotype of mouse mammary epithelium in primary culture induced by specific fetal mesenchymes. J. Cell. Physiol. 153:38I--391; 1992.

Keely, P. J.; Fong, A. M.; Zutter, M. M., et al. Alteration of collagen-dependent adhesion, motility, and morphogenesis by the expression of antisense $\alpha_{2}$ integrin mRNA in mammary cells. J. Cell Sci. 108:595-607; 1995.

Kleinman, H. K.; McGarvey, M. L.; Hassel, J. R., et al. Basement membrane complexes with biological activity. Biochemistry 25:312-318: 1986.

López-Barahona, M.; Fialka, I.; Gonzalez-Sancho, J. M., et al. Thyroid hormone regulates stromelysin expression, protease secretion and the morphogenetic potential of normal polarized mammary epithelial cells. EMBO J. 14:1145-1155; 1995.

Montesano, R.; Orci, L.; Vassalli, P. In vitro rapid organization of endothelial cells into capillary-like networks is promoted by collagen matrices. J. Cell Biol. 97:1648-1652; 1983.

Montesano, R.; Schaller, G.; Orci, L. Induction of epithelial tubular morphogenesis in vitro by fibroblast-derived soluble factors. Cell 66:697711; 1991.

Oft, M.; Peli, J.; Rudaz, C., et al. TGF- $\beta 1$ and Ha-Ras collaborate in modulating the phenotype plasticity and invasiveness of epithelial tumor cells. Genes Devel. 10:2462-2477; 1996.

Ormerod, E. J.; Rudland, P. S. Mammary gland morphogenesis in vitro: formation of branched tubules in collagen gels by a cloned rat mammary cell line. Dev. Biol. 91:360-375; 1982.

Petersen, O. W.; Rønnov-Jensen, L.; Howlett, A. R., et al. Interaction with basement membrane serves to rapidly distinguish growth and differentiation pattern of normal and malignant human breast epithelial cells. Proc. Natl. Acad. Sci. USA 89:9064-9068; 1993.

Reichmann, E.; Ball, R.; Groner, B., et al. New mammary epithelial and fibroblastic cell clones in coculture form structures competent to differentiate functionally. J. Cell Biol. 108:1127-1138: 1989.

Reichmann, E.; Schwartz, H.; Deiner, E. M., et al. Activation of an inducible c-FosER fusion protein causes loss of epithelial polarity and triggers epithelial-fibroblastoid cell conversion. Cell 71:I103-1116: 1992.
Schwimmer, R.: Ojakian, G. K. The $\alpha_{2} \beta_{1}$ integrin regulates collagen-mediated MDCK epithetial membrane remodeling and tubule formation. J. Cell Sci. 108:2487-2498; 1995.

Soriano, J. V.: Orci, L.; Montesano, R. TGF- $\beta$ l induces morphogenesis of branching cords by cloned mammary epithelial cells at subpicomolar concentrations. Biochem. Biophys. Res. Commun. 220:879-885; 1996.

Soriano, J. V.: Pepper, M. S.; Nakamura, T., et al. Hepatocyte growth factor stimulates extensive development of branching duct-like structures by cloned mammary gland epithelial cells. J. Cell Sci. 108:413-430; 1995.

Soule, H. D.: Maloney. T. M.; Wolman, S. R., et al. Isolation and characterization of a spontaneously immortalized human breast epithelial cell line, MCF-10. Cancer Res. 50:6075-6086; 1990.

Stahl, S.: Weitzman, S.; Jones. J. C. R. The role of laminin-5 and its receptor in mammary epithelial cell branching morphogenesis. J. Cell Sci. $110: 55-63 ; 1997$.

Vernon, R. B.: Angello, J.-C.: Inuela-Arispe, M. L., et al. Reorganization of basement membrane matrices by cellular traction promotes the formation of cellular networks in vitro. Lab. Invest. 66:536-547; 1992.

Wohlwend, A.; Vassalli, J.-D.; Belin, D., et al. LLC-PK 1 cells: cloning of phenotypically stable subpopulations. Am. J. Physiol. 250:C682C687; 1986.

Yang. J.; Guzman. R.: Richards, J., et al. Primary culture of human mammary epithelial cells embedded in collagen gels. J. Natl. Cancer Inst. 65:337-343: 1980.

Yang. Y.: Spitzer. E.; Mever, D., et al. Sequential requirement of hepatocyte growth factor and neuregulin in the morphogenesis and differentiation of the mammary gland. J. Cell Biol. 131:215-226; 1995.

Zuk. A.: Matlin. K. S. Apical $\beta_{1}$ integrin in polarized MDCK cells mediates tubulocrst formation in response to type I collagen overlay. J. Cell Sci. 109:1875-1889: 1996 